\title{
Abordaje Triangular. Estudio crítico
}

\section{Hamlet Fernández Díaz}

Universidade de Uberaba - Brasil

\section{Resumen}

En el trabajo se exponen consideraciones críticas sobre el Abordaje Triangular de Ana Mae Barbosa. A modo de introducción se sintetizan los problemas concretos que afrontaba la educación artística en el Brasil de la década del ochenta del siglo XX, de los que partió la investigadora para proponer su concepción de enseñanza de arte. En el cuerpo del trabajo se analizan los principales aspectos conceptuales del Abordaje Triangular. Especial énfasis se pone en la noción de contextualización, problematizándose su pertinencia como acción didáctica externa al proceso global de lectura/comprensión de obras de arte. Por último se caracteriza al enfoque pedagógico de Barbosa sobre el fondo de las concepciones posmodernas de enseñanza de artes visuales.

Palabras clave: Abordaje triangular. Arte-educación posmoderna. Artes visuales. Lectura de la obra de arte. Teoría de la recepción.

\section{Resumo}

O trabalho apresenta considerações críticas sobre a Abordagem Triangular de Ana Mae Barbosa. Como introdução, sintetizam-se os problemas específicos enfrentados pela educação artística no Brasil na década de 1980, em resposta aos quais a pesquisadora propõe sua concepção de arte-educação. No corpo do trabalho, os principais aspectos conceituais da Abordagem Triangular são analisados. Especial ênfase é colocada na noção de contextualização, problematizando-se sua pertinência como ação didática externa ao processo global de leitura/compreensão das obras de arte. Finalmente, a abordagem pedagógica de Barbosa é caraterizada sobre o pano de fundo das concepções pós-modernas do ensino das artes visuais.

Palavras-chave: Abordagem triangular. Arte-educação pós-moderna. Artes visuais. Leitura da obra de arte. Teoria da recepção.

\section{Abstract}

The work presents critical considerations on the Triangular Approach of Ana Mae Barbosa. As an introduction, the specific problems faced by artistic education in Brazil in the 1980s - from which the researcher left to propose her conception of art education - are synthesized. In the body of work, the main conceptual aspects of the Triangular Approach are analyzed. Special emphasis is placed on the notion of contextualization, problematizing its relevance as a didactic action external to the global process of 
reading / understanding of works of art. Finally, Barbosa's pedagogical approach is based on the background of postmodern conceptions of visual arts education.

Keywords: Triangular approach. Postmodern art-education. Visual arts. Reading of the work of art. Theory of reception.

\section{Résumé}

Le travail présente des considérations critiques sur l'approche triangulaire de Ana Mae Barbosa. En guise d'introduction, les problèmes spécifiques que affrontaient l'éducation artistique au Brésil dans les années 1980, desquels la chercheuse est partie pour proposer sa conception de l'éducation artistique, sont résumés. Les principaux aspects conceptuels de l'approche triangulaire sont analysés dans le corpus. Un accent particulier est mis sur la notion de contextualisation, en problématisant sa pertinence en tant qu'action didactique extérieure au processus global de lecture / compréhension d'œuvres d'art. Finalement, le texte fait une caractérisation de l'approche pédagogique de Barbosa sur les conceptions postmodernes de l'enseignement des arts visuels.

Mots-clés: Approche triangulaire. Éducation artistique postmoderne. Arts visuelles. Lecture de l'oeuvre d'art. Théorie de la réception.

\section{Introducción}

En el año 1987, la profesora e investigadora Dra. Ana Mae Barbosa comenzó a desarrollar un programa de Arte-Educación en el Museo de Arte Contemporáneo de la Universidad de São Paulo (MAC-USP). Su estrategia pedagógica fue combinar la creación estética de niños y jóvenes con sesiones de lectura de obras y contenidos propios de la Historia del Arte. Hasta el año 1993, junto a un equipo de colaboradores, la investigadora pudo experimentar con la enseñanza de las artes visuales teniendo como base la lectura de obras originales en el Museo, y utilizando reproducciones cuando se trabajaba en las escuelas de la red Municipal de Educación de São Paulo. Los resultados de la investigación serían propuestos como una epistemología posmoderna de Arte-educación denominada Abordaje Triangular, ${ }^{1}$ dada a conocer en el libro $A$ imagem no ensino da arte cuya primera edición data del año 1991. Por casi treinta años, el Abordaje Triangular de Ana Mae Barbosa ha sido la concepción de enseñanza de arte más influyente de Brasil.

El programa de arte-educación ensayado en el MAC partió de una necesidad contextual concreta. Hasta la fecha en Brasil la enseñanza de las artes visuales se había mantenido

1 "Abordagem" es el último término propuesto por la autora. En un principio le denominó Metodología Triangular, pero considerando que "metodología” es la construcción que cada profesor es capaz de desplegar en la sala de aula, cambió la nomenclatura a "Proposta", y finalmente a "Abordagem Triangular". (Barbosa, 2010a, p. XXVII) 
prácticamente ajena al contacto sistemático de los niños con imágenes artísticas (Barbosa, 2003; 2009; 2010a; 2015). La idea de introducir la lectura de obras en las clases de arte, y potenciar el trabajo creativo bajo el influjo de los referentes estéticos observados, se basaba en los siguientes argumentos: 1) si los artistas se apropian de imágenes de otros artistas, entonces no se tiene derecho a negarle esas imágenes a los niños; 2) si se prepara a los niños para leer imágenes producidas por artistas, se les está preparando para leer las imágenes que les rodean en su medio ambiente cultural; 3) la percepción pura, sin influencia de todo tipo de visualidad, no existe; 4) en el aprendizaje artístico la mímesis está presente como búsqueda de semejanza en el sentido griego, y no como copia, en el sentido romano (Barbosa, 2010a, pp. 21-22).

Sin embargo, Ana Mae Barbosa encontró fuerte resistencia entre los profesionales del área en Brasil. Muchos profesores, al ver las reinterpretaciones visuales de obras de artistas hechas por niños, acusaron a su proyecto de imponer restricciones al proceso creativo infantil. La autora explica que los cursos de licenciatura en artes existentes en aquel momento, no proveían de un conocimiento que pudiera promover una educación artística y estética sobre la base de información histórica, de la comprensión de una gramática visual y hasta de la misma creación, aunque fuera entendida como autoexpresión.

Por su puesto, dicho fenómeno tenía sus razones históricas. No fue hasta 1971, con la Ley Federal n. 5.692 de "Diretrizes e Bases da Educação", que en Brasil la educación artística pasó a ser obligatoria tanto en la enseñanza fundamental como en la media. Para responder a la demanda de profesores que generó dicha Ley, se crean en el año 1973 los cursos de licenciatura en Educación Artística. Sin embargo, aquellos cursos solo tenían 2 años de duración y fueron pensados para formar a un profesor polivalente, capaz de dar clases de música, teatro, artes visuales, dibujo, danza; todo al mismo tiempo. Para Ana Mae Barbosa (2010a), se trató de un "absurdo epistemológico" intentar formar a un joven en apenas dos años, para luego desempeñarse como profesor de tantas disciplinas artísticas.

Los resultados de esos cursos de licenciatura de dos años, Ana Mae Barbosa los pudo verificar en 1983, cuando realizó un estudio en el que entrevistó a 2500 profesores de arte de escuelas públicas de São Paulo. El principal hallazgo fue que en su mayoría consideraban que el desarrollo de la creatividad era el primer objetivo de su enseñanza. Para los que hacían énfasis en las artes visuales, el concepto de "creatividad" era equivalente a espontaneidad, autoliberación, originalidad. Resultaba evidente que el problema de fondo era de formación, y aquella concepción de la creatividad respondía más al sentido común que a una formación teórica (Barbosa, 2010a).

La autora cita otra investigación del mismo año 1983, en la que se verificó que los libros didácticos de arte eran utilizados por el $82,8 \%$ de una muestra de 150 profesores. $^{2}$ Ana Mae Barbosa refiere que aquellos datos hacían pensar en una contradicción, porque

2 Ana Mae Barbosa se refiere a una pesquisa realizada por Heloísa Ferraz e Idméa Siquerira publicada en el año 1987 (Arte Educação: Vivência, Experimentação ao Livro Didático. Sao Paulo: Loyola). 
los libros didácticos de la época eran apenas modernizaciones de libros usados en la enseñanza de dibujo geométrico en los años cuarenta y cincuenta. Y en esos manuales no podía encontrarse ninguna preocupación por el desarrollo de la autoliberación, que era el objetivo que los profesores estaban declarando como la prioridad de su enseñanza. Se comprobaba así una falta de correspondencia entre los objetivos que se declaraban y la práctica concreta de la enseñanza de arte.

El otro hecho significativo detectado en el análisis cruzado de las dos pesquisas sobre profesores era que, en Brasil, aun en la década del ochenta, el tipo de enseñanza de arte que predominaba en las salas de aula se basaba en el dibujo geométrico así como en otros ejercicios formales. De esa manera, llega Ana Mae Barbosa a la constatación de una carencia fundamental: ni la apreciación artística ni la Historia del Arte tenían presencia en los programas de enseñanza. El contacto con imágenes en la escuela se limitaba a la de los libros didácticos, de dudosa calidad estética. Las visitas a exposiciones o museos eran sumamente esporádicas. La fuente de consumo de imágenes dominante era, por tanto, la televisión, un medio al que todos los niños, de una forma u otra, tenían acceso. Su diagnóstico final fue que después de 17 años de instaurada en el país la obligatoriedad de la enseñanza de arte, no se podía afirmar que se hubiese desarrollado una arte-educación de calidad estética.

Con base en esas necesidades y problemas concretos verificados en el contexto brasileño de los ochenta, Ana Mae Barbosa propone un abordaje pedagógico que asume el arte no solo como un instrumento para el desarrollo de habilidades, ya sean técnicas o cognitivas, sino también como un componente esencial del desarrollo cultural de un país. La enseñanza de arte debía posibilitar, ante todo, de manera democrática e inclusiva, el acceso de los niños a su herencia cultural; y para ello se hacía necesario conjugar la apreciación, la historia y la creación artística como acciones contextualizadas e interrelacionadas, desde los primeros años de escolarización.

En la dimensión política, Ana Mae Barbosa escribía sin ambages a finales de los ochenta que la Nueva República no había propiciado ningún avance en el área de la enseñanza del arte. Convocaba a exigirle al Estado su responsabilidad en el desarrollo de una arte-educación de calidad, implementando acciones más efectivas en lo que se refería a los presupuestos conceptuales, así como estrategias más adecuadas para estimular la creación y la apreciación artística en todos los estrados de la sociedad: "Sabemos que arte não é apenas socialmente desejável, mas socialmente necessária" (Barbosa, 2010a, p. 5).

Su proyecto de arte-educación apuntaba desde entonces a un objetivo englobante situado en una dimensión social, que lo hacía converger con un principio de "política cultural". La gran misión de la enseñanza de arte debía ser la de equilibrar la asimetría históricamente existente entre los códigos estético-culturales manejados por las llamadas élites, y los de las grandes mayorías de la sociedad, desposeídas de las competencias culturales necesarias para el consumo de arte.

En sintonía epocal y epistemológica con los Estudios Culturales ingleses, la pedagogía 
crítica y progresista de Paulo Freire, lo mejor del pensamiento cultural progresista latinoamericano que se venía formando desde la década del sesenta, así como con lo más avanzado de las teorías en arte-educación norteamericanas e inglesas de la época, Ana Mae Barbosa entiende la formación de un espectador competente, conocedor, con capacidad de juicio crítico, como una necesidad de índole política, de justicia social, de eliminación de las desigualdades en el plano de lo simbólico, de democratización del acceso al capital cultural más refinado de un pueblo, como lo es su arte.

En lo que sigue se expone una síntesis de un estudio crítico ${ }^{3}$ sobre el Abordaje Triangular, resultado de una investigación bibliográfica de carácter cualitativo, cuyo objeto de estudio fundamental lo constituyó la producción teórica de la autora sobre la enseñanza de las artes visuales en el contexto escolar. Proponemos una serie de consideraciones críticas sobre los principales aspectos conceptuales del Abordaje Triangular, tales como: alfabetización visual, creación basada en la relectura visual, contextualización, lectura de la obra de arte. La revisión a nivel teórico de las ideas de la autora permite concluir que su argumentación de índole contextualista sobre la necesidad e importancia de la enseñanza del arte es plenamente vigente en Brasil; mientras que su concepción epistemológica de la arte-educación sigue siendo un estímulo a la reflexión, y admite ser actualizada, ampliada y profundizada con base en las propias intuiciones teóricas de la autora.

El trabajo se inscribe en el marco de una investigación posdoctoral en curso, que estudia las concepciones de enseñanza de las artes visuales en Brasil que ponen especial énfasis en la lectura/comprensión de la obra de arte.

\section{Aspectos conceptuales del Abordaje Triangular}

Ana Mae Barbosa considera que su Abordaje Triangular parte de una síntesis entre dos teorías curriculares que comenzaron a polarizarse a partir de la segunda mitad de la década de 1950: una que continuaba abogando por la idea de que los contenidos se mantuvieran centrados en los estudiantes, defendiendo la "intuición" como origen de la expresión personal y rechazando por tanto los procesos lógicos y conscientes como base de la creación artística (libre-expresión); y otra corriente, que comienza a considerar la importancia de las disciplinas, en su especificidad y autonomía, porque la enseñanza de arte debía desarrollar un mayor nivel profesional en la escuela y para ello resultaba imprescindible introducir contenidos conceptuales. Dicha corriente cristalizaría a partir de la década de 1980 en los Estados Unidos con la denominación Discipline Based Art Education (DBAE), y en Inglaterra como Critical Studies in Art Education Proyect (CSAE);

3 Utilizamos la categoría estudio crítico en el mismo sentido de "examen crítico" o "actitud crítica", tal como son definidos por Karl Popper (1980): un método de análisis que subyace a toda discusión racional sobre los problemas científicos y las soluciones propuestas, las conjeturas y las refutaciones. 
ambas como refutación del paradigma modernista de la libre-expresión. ${ }^{4}$

Situándose en un punto intermedio, sabiendo que la teoría modernista de la libreexpresión resultaba insuficiente, pero temiéndole al peligro de derivar hacia un tipo de academicismo dada la separación en disciplinas que proponía la DBAE, al tiempo que reconocía la conquista que representaba desenvolver en simultaneo diversas formas de conocimiento en un mismo proceso de enseñanza-aprendizaje, Ana Mae Barbosa define de la siguiente manera su orientación:

Um currículo que interligasse o fazer artístico, a análise da obra de arte e a contextualização estaria se organizando de maneira que a criança, suas necessidades, seus interesses e seu desenvolvimento estariam sendo respeitados e, ao mesmo tempo, estaria sendo respeitada a matéria a ser aprendida, seus valores, sua estrutura e sua contribuição específica para a cultura (Barbosa, 2010a, p. 36).

En su perspectiva, aprender arte implica un conocimiento interrelacionado de las tres acciones, y ninguna de las tres dimensiones en individual sería suficiente para proponer una epistemología de la arte-educación. Como ya hemos referido, su propuesta contó desde el inicio con una fuerte resistencia, en primer lugar entre los propios arteeducadores, porque en Brasil siempre había dominado en la enseñanza de las artes plásticas el trabajo en atelier, primero el aprendizaje de técnicas y procedimientos del dibujo geométrico, y después la concepción modernista de la libre-expresión (Barbosa, 2009; 2015). Ana Mae Barbosa nunca negó que la acción de "crear" es de suma importancia para la enseñanza del arte, pero defendía la idea de que la sola creación por sí misma no es suficiente para desarrollar una cultura apreciativa, tanto de las imágenes producidas por los artistas como las del mundo cotidiano que nos rodea.

Dada la profusión de imágenes de todo tipo que caracteriza a la sociedad contemporánea, la profesora e investigadora señala que resultaba impostergable emprender una "alfabetización visual", eso es, desarrollar habilidades para la lectura crítica de la imagen. Y esas habilidades podían ser proporcionadas a través del contacto sistemático con obras de arte desde el nivel fundamental de enseñanza. La autora parte de la convicción de que formando a los sujetos en el entendimiento del arte, se les forma de manera implícita para la comprensión crítica de la imagen, sea esta de tipo artístico o no.

La noción de "alfabetización visual" como formación en la lectura crítica de la imagen recuerda el concepto de "alfabetización política" de Paulo Freire (2004), que implica una superación de la percepción ingenua de la realidad por una percepción crítica. Sin esa percepción crítica del "contexto concreto" no sería posible el proceso de "concientización”, con el que Freire se refiere a la praxis teórico-práctica (reflexión-

$4 \quad$ La DBAE norteamericana proponía un tipo de enseñanza de arte basada en disciplinas, a saber: Producción artística, Historia del Arte, Crítica y Estética (Eisner, 2005). Por su parte, el CSAE inglés defendía la idea de que la creación artística y la apreciación eran acciones complementares, apostaba por el desarrollo de la conciencia crítica de los alumnos, por el contacto directo con obras y artistas en museos y galerías, así como por la incorporación de contenidos de la historia del arte (lavelberg, 2017). 
acción) que genera el "contexto teórico" desde el cual el hombre actúa para transformar su realidad. Aunque Ana Mae Barbosa no establece de manera explícita esa articulación conceptual en $A$ imagem no ensino da arte, podemos inferir que su noción de "alfabetización visual" tiene como horizonte englobante a la "alfabetización política", la cual solo es posible mediante una "educación liberadora" que rompa el círculo vicioso de la "domesticación".

Ahora bien, llama la atención que la "alfabetización" por la que aboga Ana Mae Barbosa se centre únicamente en la imagen, o en el plano de lo estrictamente visual, cuando a la altura de finales de los ochenta las prácticas artísticas posmodernas ya habían llevado a cabo una desjerarquización de los sentidos. Procedimientos como el performance, los environments, el body art, el arte abyecto u escatológico, el instalacionismo, las intervenciones públicas, la escultura experimental, el arte conceptual, el land art, y un largo etcétera, trabajan sobre todo el aparato sensorial del hombre, y no exclusivamente sobre el sentido de la vista.

La tradición de la estética filosófica occidental, desde Platón, siempre consideró a la vista y al oído como los únicos sentidos cognoscitivos, siendo el resto considerados sentidos inferiores, por creerlos más próximos de la animalidad. Ese tipo de construcción teórica creó a la larga una especie de metafísica de los sentidos, con una estructura jerárquica muy bien definida. También, sobre ese fundamento metafísico naturalizado de la jerarquía de la vista y el oído, Occidente a lo largo de la historia ha despreciado y considerado como culturas bárbaras, incivilizadas e inferiores, a todos aquellos pueblos cuyos sistemas culturales se estructuraron sobre la base de la dominancia de algunos de los tres sentidos considerados inferiores (Classen; Le Breton, 2007; Welsh, 2011).

Por otro lado, el mundo que nos rodea no solo es visual y sonoro. Los sentidos del olfato, el gusto y el tacto intervienen también en una infinidad de prácticas culturales con un fuerte componente estético. Los rituales del amor serían impensables sin el sentido del tacto. En las ceremonias religiosas donde la música y el baile son protagónicos, como las de origen africano, la experiencia estética/mística se torna sinestésica. La inmensa mayoría de las festividades populares propician el goce de los cinco sentidos; siendo la comida, en todos los tiempos y en todas las culturas, síntesis estética multisensorial de una tradición histórica.

Por tanto, el desarrollo de la cognición sensible - como definiría Baumgarten al universo de lo estético para diferenciarlo del campo de la lógica - debe ser propiciado desde la temprana infancia de manera integral, y no solo haciendo énfasis en el "ver". Solo un desarrollo pleno de todos los sentidos (o de aquellos que se posean) permite al individuo una interacción mucho más rica e intensa con el universo cultural, que siempre es multisensorial. Una arte-educación que pretenda ser multicultural y descolonizadora no debiera descuidar el aspecto multisensorial de la experiencia estética, tal y como la propician muchas de las prácticas artísticas posmodernas (Román, 2016).

Potenciar el trabajo de creación de los niños bajo el influjo de las obras artísticas observadas en clase es otra de las ideas defendidas por el Abordaje Triangular de Ana 
Mae Barbosa. Ahora bien, resulta polémica la manera en que el denominado fazer basado en la releitura ${ }^{5}$ puede incidir en el desarrollo de habilidades interpretativas de textos complejos como son las obras de arte. Realizar un dibujo, una pintura, un collage, una escultura etc., se tenga o no como modelo un referente artístico, desde el punto de vista semiótico, implica habilidades diferentes a las que se requieren para la comprensión interpretativa de una obra de arte. Crear una metáfora es sustancialmente diferente a interpretarla (Eco, 1988, 1992; Jakobson, 2003). De ahí que la crítica de arte y la creación artística sean profesiones tan distintas, que requieren formaciones y habilidades específicas.

En nuestra opinión, ambas habilidades creativas se complementan en la medida en que la lectura/comprensión sistemática de obras de arte aporta un horizonte reflexivo de problemáticas que en tanto conocimiento apropiado por el estudiante, entrarán de manera espontánea en su proceso de creación artística. Quizás lo que deba potenciarse como inspiración para la creación son las ideas importantes o problemáticas relevantes, independientemente de que los estudiantes decidan trabajar, o no, a partir de las soluciones formales que modelan las obras con las que han estado en relación. Si la lectura de una o varias obras de arte permite movilizar una gama sustancial de contenidos diversos, por qué no organizar metodológicamente el proceso de creación con base en esa experiencia cognoscitiva, en vez de con el aspecto meramente formal de la obra. ${ }^{6}$

Ana Mae Barbosa se ha visto en la necesidad de precisar que ella nunca recetó la "releitura", en el sentido de copia mimética, de crear copiando obras de arte. Que esas son simplificaciones, alguna de ellas mal intencionadas, de ciertos comentadores de su teoría, o errores cometidos en la práctica por arte-educadores. Por eso decidió cambiar el término "releitura" por el de "interpretação", para referirse a la acción de crear a partir de referentes artísticos (Barbosa, 2010a, p. XXIX). Sobre la reducción del "fazer artístico à releitura" que se comenzó a evidenciar en la práctica educativa en Brasil, comenta la autora:

O erro mais grave é o de restringir o fazer artístico, parte integrante da triangulação, à releitura de obras. Outro é pensar que há uma hierarquia de atividades, isto é, primeiro a leitura da obra de arte, depois a contextualização e finalmente o fazer, a criação. Esta não é uma interpretação correta. (...)

A releitura é uma atividade possível e quanto mais problematizadora mais criadora. (...) Mas o perigo da reprodução improdutiva ronda as releituras. Ando tão alarmada com a péssima qualidade de pensamento visual resultante de releitura em que me peguei outro dia desrecomendando completamente a releitura em uma palestra. (Barbosa, 1998, pp. 39-40)

$5 \quad$ "Releitura" en portugués alude a crear a partir de algo, de un referente, aunque la acción no implica necesariamente una copia exacta o meramente mimética, reproductiva. Puede haber creatividad interpretativa en la "releitura".

6 Por ejemplo, la teoría del Currículo Integrado propone precisamente que la creación artística de los estudiantes sea incentivada a partir de las ideas relevantes que han sido estudiadas de manera articulada por todas las disciplinas (Parsons, 2008). Ana Mae Barbosa también ha llegado a sostener que un currículo "alocentricamente" integrado es más eficiente, definiendo cuatro razones que fundamentan la eficiencia del Currículo Integrado (Barbosa, 2010b, pp. 25-26). 
Otro aspecto al que Ana Mae Barbosa le otorga suma importancia es el de la "contextualización". La lectura debe ser siempre enriquecida con información sobre el contexto histórico, social, antropológico etc. La autora considera que se trata de la condición epistemológica básica de nuestro momento histórico (posmodernidad), y no un mero vórtice del proceso de aprendizaje. Con la acción de contextualizar no se refiere en exclusivo a la vida de los artistas, los estilos y demás cuestiones historiográficas, sino a poner la obra en contexto, mostrar la relación de la obra y del artista con el medio de la época:

Não adotamos um critério de história da arte objetivo e cientifizante que seja apenas prescritivo, eliminando a subjetividade. Sabemos que em historia da arte é importante conhecer as características das classificações de estilo, a relação de uma forma de expressão com as características sociais e com a psicologia social da época, mas analisar as características formais do objeto no seu habitat de origem não pode ser o escopo máximo da história da arte. Cada geração tem direito de olhar e interpretar a história de uma maneira própria, dando um significado à história que não tem significação em si mesma. (...) A reconstrução do passado é apenas um dado e não tem um fim em si mesma, especialmente no que se refere à história da arte (Barbosa, 2010a, p. 39).

Ana Mae Barbosa intenta conservar el reducto de la "subjetividad", aun cuando se haga un análisis histórico que sitúe a la obra en su contexto de origen. Hace explícita una visión móvil de la comprensión. La historia sería siempre una mediación que se hace presente, y esa mediación exige ser reconstruida y apropiada, cada vez, por la subjetividad humana. Por eso cada momento histórico abre nuevas posibilidades interpretativas. Toda generación no solo tiene el derecho a mirar e interpretar la historia de manera propia, sino más bien está obligada a hacerlo; porque, como dirían Heidegger y Gadamer, se comprende desde el presente y para el presente, y el círculo de la comprensión nunca se cierra del todo: la comprensión humana es proyectual, eso es, tiene carácter de futuridad. No existe un único significado de origen, ni un significado final, de destino (Gadamer, 1998).

La autora le presta también una especial importancia al objeto-arte, en tanto artefacto histórico que se nos sitúa ante la vista; aquí, hoy. En su opinión podemos tener una experiencia directa basada en la fuente de información que nos proporciona la obra de arte; por ello no se debe renunciar nunca a dialogar con el objeto desde su especificidad intrínseca, es de vital importancia entender el objeto a partir de sí mismo. En el caso específico de las artes visuales, advierte que paradójicamente el tiempo existe en la materia y el espacio, eso es, se configura prioritariamente en el orden visual:

As artes que se configuram pela materialidade organizada espacialmente são o testemunho mais objetivo do tempo. Em arte, a relação tempo histórico-tempo individual determina os cortes sequenciais e a interpretação do objeto. (...) Em arte, a historia é destruída pela fruição, aqui e agora, cada dia pelo observador pervasivo. O tempo fenomenológico é mais importante para a apreciação do que o tempo histórico (Barbosa, 2010a, pp. 106-107).

Ana Mae también señala que la cognición en la arte-educación solo puede emerger del envolvimiento/desenvolvimiento existencial del alumno; la información con la que el profesor trabaja no debe ser nunca impuesta, ni puede ser emotivamente neutral, 
porque: "a consciência da experiência estética explicitada organiza os significados aqui e agora", y, "a mutabilidade destes significados depende muito mais da consciência interrogante do que da mutabilidade histórica" (Barbosa, 2010a, p. 105).

De lo anterior se pudiera inferir que Ana Mae Barbosa intenta articular tres dimensiones diferentes: la subjetividad de quien comprende; la mediación histórica a través de la cual los artefactos llegan a nosotros; y la propia especificidad de los objetos artísticos. Haciéndonos eco de sus criterios, diríamos que una enseñanza del arte a través de su recepción debe intentar conjugar esas tres dimensiones en un mismo proceso de enseñanza-aprendizaje: que el estudiante comprenda desde sí mismo, involucrándose emocional e intelectualmente en el proceso; que comprenda el artefacto sobre su horizonte histórico, apropiándose de esa historicidad pero desde su aquí y ahora existencial; y que la interpretación comience, en primer lugar, a partir de la intencionalidad semántica y estética intrínseca a la obra.

Ahora bien, esa triangulación, desde una perspectiva hermenéutica, y también desde una semiótica de la recepción, se tiende a concebir como un proceso en el que perdería sentido establecer una diferenciación entre "lectura" y "contextualización". Si asumimos que el objetivo de la lectura de una obra es la comprensión, que los significados deben ser organizados aquí y ahora por una conciencia interrogante que superpone el tiempo individual al tiempo histórico (como bien advierte Ana Mae), entonces la llamada acción de "contextualización" es siempre implícita a la lectura, por lo que resulta redundante su diferenciación. La propia Ana Mae Barbosa ha comentado que optó por la designación "leitura de obra de Arte" inspirada en el movimiento Reader Response. En especial, porque para esta vertiente norteamericana de la teoría de la recepción literaria: "O leitor e o objeto constroem a resposta à obra numa piagetiana interpretação do ato cognitivo e, mais ainda, vigotsquiana interpretação de compreensão do mundo. Assimilação e acomodação na relação leitor-objeto (reader - response) são os processos fundamentais que se impõem" (Barbosa, 1998, p. 35).

El contexto de la interpretación se abre, se construye y solo puede llegar a existir a partir del momento en que obra y receptor entran en una relación dialógica. Para un autor como Wolfgang Iser, figura central de la teoría de la recepción literaria, un polo estético sería esencialmente diferente a la estructura o polo artístico creado por el autor, porque el primero solo puede surgir mediante el acto de concreción realizado por el lector. ${ }^{7}$ De dicha polaridad, Iser infiere que el verdadero espacio de la obra de arte se da en la convergencia de texto y lector, y posee un carácter esencialmente virtual:

A esta virtualidad debe la obra de arte su dinámica, que, por su parte, es la condición de los efectos que produce. El texto se actualiza, por lo tanto, sólo mediante las actividades de una conciencia que lo recibe, de manera que la obra adquiere su auténtico carácter procesal sólo

$7 \quad$ El concepto de concreción, así como el de polo estético y polo artístico, Wolfgang Iser los toma prestados de Roman Ingarden (1987). Para el autor polaco, concreción significaba completamiento y actualización por parte del receptor, de los lugares de indeterminación que son potenciales en toda obra literaria. 
en el proceso de su lectura (Iser, 2003, p. 488).

La "lectura" así entendida no puede dejar de "contextualizar" porque, podríamos agregar, comprender una obra artística implica entrar en diálogo con una "otredad de sentido" (Gadamer, 1991; 1998), o con una "estructura semántica ambigua" (Eco, 1988; 1992; Jakobson, 2003; Mukařovský, 2000; Sonesson, 1997). Para comprender esa otredad, para reducir su ambigüedad semántica, se debe hacer hablar al texto "extraño" creando hipótesis interpretativas, se debe desencadenar un proceso de continuas abducciones que nos permita entrar en su historicidad; mas, resulta imposible hacerlo si no es desde la propia historicidad de quien intenta comprender. Obra y receptor poseen ambos una historicidad; las categorías trabajadas por la estética de la recepción de intencionalidad de la obra e intencionalidad del receptor derivan de esa doble historicidad que entra en acción en todo proceso dialógico de comprensión. Desde esa perspectiva teórica, la "contextualización" solo adquiere sentido como fusión de historicidades, por lo que en tanto acción metodológica no puede pensarse o instrumentarse como algo que se suma, o apoya "desde afuera", el proceso de lectura.

Para una hermenéutica marxista posmoderna, como la desarrollada por Fredric Jameson (1989), por ejemplo, la noción modernista de una "Historia" con pretensiones de universalidad siempre fue una ficción metafísica. Siguiendo a Louis Althusser, Jameson argumenta una noción posmoderna de Historia entendida como un tipo de "referente" muy singular que siempre se nos presenta como "causa ausente", a saber: en tanto totalidad la Historia es una nebulosa de contenido que es preciso hacer inteligible, convertir en conocimiento; y esa operación del pensamiento se objetiviza a través de procesos de textualización, eso es, de producción de narrativas: "la historia no es un texto, una narración, maestra o de otra especie, sino que, como causa ausente, nos es inaccesible salvo en forma textual, y que nuestro abordamiento de ella y de lo Real mismo pasa necesariamente por su previa textualización" (Jameson, 1989, p. 30). ${ }^{8}$

Siguiendo a Jameson, pudiéramos argumentar que la historicidad de la obra de arte es también una causa ausente que solo se nos vuelve inteligible en la medida en que logramos textualizarla; justo lo que hace la interpretación, construir narrativas. Siguiendo la perspectiva culturalista posmoderna de Ana Mae Barbosa, podemos aventurarnos a sostener que esa textualización es también contextualización, porque la interpretación involucra la historicidad del sujeto (otra causa ausente). Es en ese sentido que volvemos a subrayar una comprensión de la acción de "contextualizar" como fusión de historicidades: la de la obra y la del receptor. En el diálogo interpretativo con el arte no solo producimos narrativas sobre las obras, también nos reescribimos a nosotros mismos en el proceso; textualizamos fragmentos de nuestra experiencia individual, llenamos el vacío de la ausencia de lo que ya aconteció y nos aproximamos a nosotros mismos de manera consciente. No existe comprensión desinteresada, nuestro esfuerzo interpretativo de abducción está condicionado desde siempre por intereses,

No se debe entender la noción de textualización o narrativización como reducción o sometimiento de toda comprensión al plano del lenguaje verbal. Se puede narrar y producir textos con cualquier tipo de sistema de significación (lenguajes), o con cualquier materialidad que sea organizada con intención comunicativa. 
preocupaciones, expectativas, pre-juicios, experiencias previas y visión de mundo en general (estructuras de comprensión).

Por eso, para que la educación a través del arte sea verdaderamente liberadora o descolonizadora, no basta valorizar la producción simbólica o las identidades locales, regionales o nacionales, potenciar las historias particulares, propiciar el diálogo intercultural, enseñar a leer críticamente etc. Si en el proceso de lectura la “contextualización” no es concretizada por el propio estudiante, si la textualización de lo que se debe comprender no involucra su propia experiencia existencial, que es en última instancia lo que anima y moviliza un esfuerzo interpretativo, entonces la autoapropiación narrativa de la historia individual y colectiva no se produce. La experiencia que nos provoca el arte puede convertirse en un hecho liberador o emancipatorio en la medida en que el diálogo con las obras nos motive a una reescritura crítica, en primer lugar, de nuestras propias convicciones, certezas "infalibles", o visión de mundo. Ese es uno de los aspectos que más debe enfatizar una educación a través del arte: la alfabetización cultural y política pasa por la capacidad de apropiación crítica del propio devenir existencial, y el diálogo con el arte es una provocación constante a ese angustiante proceso de concientización.

Ana Mae Barbosa volvería sobre el tema de la "contextualización" en la revisión crítica de su Abordaje Triangular efectuada en Arte-educação pós-colonialista no Brasil: aprendizagem triangular. En aquel texto, combatía las acusaciones de ciertos detractores de su propuesta, que la tildaban de ser mera copia de la DBAE norteamericana. La autora deja claro que su triangulación parte de una diferenciación esencial con el modelo estadounidense porque aquel disciplinarizaba la enseñanza de arte en la perspectiva modernista del currículo estructurado en disciplinas; mientras, su propuesta optó por "acciones" que operan como componentes curriculares. En su enfoque la Historia del Arte se sustituye por la acción de "contextualización", buscando ampliar el espectro de la enseñanza de arte más allá del dato meramente histórico para entrar en los terrenos de lo social, lo psicológico, antropológico, geográfico, ecológico y hasta biológico.

Contextualizar é estabelecer relações. Neste sentido, a contextualização no processo ensinoaprendizagem é a porta aberta para a interdisciplinaridade. A redução da contextualização a historia é um viés modernista. É através da contextualização que se pode praticar uma educação em direção à multiculturalidade e à ecologia, valores curriculares que definem a pedagogia pós-moderna acertadamente defendidos pelos Parâmetros Curriculares Nacionais (PCN) (Barbosa, 1998, p. 38).

De igual manera, pudiéramos decir que interpretar creativamente una obra de arte es establecer relaciones. Cuando en un proceso de enseñanza-aprendizaje la compresión colectiva de estudiantes y profesor logra movilizar a partir del diálogo con la obra un conjunto de contenidos diversos, se entra inevitablemente en un proceso interdisciplinar de producción de conocimiento. La puerta abierta a la interdisciplinariedad y a la interculturalidad en la enseñanza de arte se garantiza con el entrenamiento sistemático de los estudiantes para llevar a cabo procesos de interpretación cada vez más creativos, expansivos, audaces, en los que se involucre la mayor cantidad de conocimiento posible. Por tanto, el término contextualizar es intercambiable con el de interpretar, textualizar, 
narrativizar, y todos son condiciones básicas de la compresión. En palabras de la propia Ana Mae: "leitura é interpretação", y, "as interpretações de uma obra podem ser tão diferentes, tantos quanto forem os interpretantes” (Barbosa, 1998, p. 46).

Si el profesor no organiza y dirige con creatividad el proceso de lectura/comprensión de obras de arte, puede acontecer el fenómeno muchas veces advertido por la propia Ana Mae Barbosa, así como por otros muchos investigadores del área: la llamada “contextualización" se reduce a una acción en la que el profesor superpone a la obra una serie de informaciones y datos biográficos, históricos, sociales, estilísticos, estéticos etc., que difícilmente un niño o adolescente logrará articular de manera orgánica en un proceso de comprensión estructurado desde su propia intencionalidad (historicidad) como receptor. ${ }^{9}$ Es por ello que en nuestra opinión, declarar la contextualización como una acción, y la lectura de la obra como otra acción, puede haber estado funcionando como la causa de fondo que propicia que algunos arte-educadores hagan una instrumentación metodológica esquemática y poco creativa del Abordaje Triangular. A este respecto resulta muy ilustrativo el siguiente análisis de la artista y profesora Terezinha Losada:

[...] a "contextualização" nas formulações educacionais de Ana Mae também é um exercício holístico. Para ela, o fazer e o apreciar visam desencadear uma elaboração existencial e cognitiva, que envolva a descoberta e a memória, a imaginação e a história, a afetividade e a crítica, a experimentação e o código, o individual e o coletivo... (...) No entanto, conforme foi mencionado anteriormente, os fantasmas da pedagogia tradicional são atávicos, de modo que muitas e muitas propostas educativas que se dizem pautadas na triangulação proposta por Ana Mae, de fato sucumbem nas cisões esquizofrênicas do tradicionalismo. O sintoma mais raso e recorrente desse problema é o professor iniciar a aula fazendo uma "explanação" sobre a vida e a época de determinado artista, depois mostrar várias de suas obras, fartamente disponíveis na internet, elegendo, ele mesmo, uma delas para ser "apreciada" com os alunos. Feito isso, os alunos são convidados a "fazer uma cópia" daquela obra, a título de releitura. (Losada, 2017, 234-236)

Precisamente, uno de los equívoco en el que han incurrido muchos profesores de arte en Brasil es el de designar las tres acciones de la triangulación como fases. Esos errores o incomprensiones han llevado a Ana Mae Barbosa (1998) a intentar clarificar todo lo posible sus postulados:

Não se tratam de fases da aprendizagem, mas de processos mentais que se interligam para operar a rede cognitiva da aprendizagem.

(...) me assusta a idéia do professor que, a pretexto de trabalhar com a leitura da obra de arte e com a contextualização, dê longas preleções discursivas, isto é, historicize acerca de um artista ou leia uma obra para alunos reduzidos à passividade. (...)

$9 \quad$ Una de las conclusiones a las que llega Abigail Housen en su investigación sobre el desarrollo estético, es que "los niños que han aprendido una serie de hechos o información propios de los expertos, no suelen dar muestras de dicha información en su muestreo de pensamiento estético". Su pesquisa empírica desarrollada durante décadas, que excede la cifra de 6000 entrevistas a sujetos de más de 15 culturas diferentes, le permite afirmar también que "pretender enseñar a los principiantes a pensar como los expertos es un esfuerzo inútil". (Housen, 1999) 
Leitura da obra de arte é questionamento, é busca, é descoberta, é o despertar da capacidade crítica, nunca a redução dos alunos a receptáculos das informações do professor, por mais inteligentes que elas sejam. A educação cultural que se pretende com a Proposta Triangular é uma educação crítica do conhecimento construído pelo próprio aluno, com a mediação do professor, acerca do mundo visual e não uma "educação bancaria". (p. 40)

Como queda claro en este fragmento, la concepción epistemológica de fondo de la investigadora en arte-educación más renombrada de Brasil no deja dudas ni espacio a los esquematismos, la fragmentación del proceso de enseñanza-aprendizaje, o a la educación meramente reproductiva. Ana Mae Barbosa da suficientes pistas teóricas para enmarcar la noción de "contextualización" en una conceptualización más englobante del proceso de lectura/comprensión del arte. En la breve revisión crítica que escribiera como introducción a la última edición de $A$ imagem no ensino da arte, la propia autora expresa que hoy la metáfora del triángulo no se corresponde con exactitud a la organización metodológica deseada, pareciéndole más adecuada la figura del zigzag ("ziguezague"), pues la contextualización debe operar tanto en el proceso de lectura como en el proceso de creación artística. De esta forma, sugiere una introyección de la "contextualización" hacia los procesos más englobantes de creación estética, y lectura/ comprensión de obras de arte.

No es gratuito que una de las características del Abordaje Triangular que más han enfatizado los investigadores del área es precisamente su carácter flexible, abierto, en constante transformación y adecuación a los nuevos imperativos históricos que van surgiendo; una cualidad que Ana Mae Barbosa ha predicado con el ejemplo, dada la voluntad de revisión crítica de sus propios postulados.

Quizás en gran medida a esa flexibilidad debe hoy el Abordaje Triangular su gran vitalidad a casi 30 años de existencia, porque muchos arte-educadores e investigadores lo han hecho suyo en la práctica y en la reflexión teórica, convirtiéndose así en una concepción de arte-educación que se continúa construyendo en colectivo. ${ }^{10}$ Un libro como A Abordagem triangular no ensino das artes e culturas visuais (Barbosa y Cunha, 2010), que compila 27 trabajos de investigadores en arte-educación de todo Brasil (seleccionados por la propia Ana Mae y sus colaboradores), y más recientemente el dossier que le dedicara la revista GEARTE (2017), son apenas botones de muestra de lo comentada, discutida, problematizada, aplicada, extrapolada hacia otros campos de la educación etc., que ha sido esta propuesta posmoderna de enseñanza del arte desde que fuera dada a conocer en el año 1991.

\section{Consideraciones finales}

10 Un buen ejemplo de ello es el libro de Terezinha Losada A interpretação da imagem: subsídios para o ensino de arte (2011). Sin romper con los marcos generales del Abordaje Triangular, esta autora intenta profundizar en la problemática de la interpretación recurriendo a teorías semióticas como las de Charles S. Pierce y Roman Jakobson, entre otros autores. 
Para Elliot W. Eisner (1995), han existido por lo menos dos tipos de argumentos bien diferenciados para fundamentar la importancia del arte en la educación escolar: la "contextualista" y la "esencialista". La justificación contextualista enfatiza las consecuencias instrumentales de la enseñanza de arte, con base en las necesidades y características tanto de los estudiantes, la comunidad, así como de la sociedad en su conjunto. Por su parte, la justificación esencialista se basa en la especificidad cultural del arte, en el tipo de experiencia emocional, comunicativa y cognoscitiva que solo el arte puede proveer. Los objetivos y las características del tipo de enseñanza por la que se opte dependerá en cada caso, según Eisner, del tipo de concepción que se tenga del arte y de su potencialidad formativa, ya sea como un medio para alcanzar otros fines, o como un fin en sí mismo.

Consideramos que los argumentos desarrollados por Ana Mae Barbosa en la sistematización de su Abordaje Triangular, para defender y reivindicar el lugar del arte en la educación escolar, articulan tanto justificaciones esencialistas como contextualistas. Su propuesta pedagógica parte de una afirmación de la potencialidad cognoscitiva intrínseca al arte:

Arte não é apenas básica, mas fundamental na educação de um país que se desenvolve. Arte não é enfeite. Arte é cognição, é profissão, é uma forma diferente da palavra para interpretar o mundo, a realidade, o imaginário, e é conteúdo. Como conteúdo, arte representa o melhor trabalho do ser humano. Arte é qualidade e exercita nossa habilidade de julgar e de formular significados que excedem nossa capacidade de dizer em palavras. E o limite da nossa consciência excede o limite das palavras (Barbosa, 2010a, p. 4).

A su vez, Barbosa sumó a su argumentación un tipo de justificación basada en "razones pragmáticas", diríamos instrumentales. Desarrollar la creatividad y la vocación por lo estético desde los primeros años de escolarización es para la autora una cuestión estratégica y esencial para el desarrollo del país, porque en su criterio a través del arte se puede potenciar en los estudiantes habilidades y competencias que son fundamentales para la formación posterior del tipo de profesional que se desenvuelve en áreas como el diseño y todas sus aplicaciones, la televisión, la publicidad, la industria textil, el urbanismo, la arquitectura y la industria cultural en general; áreas que son extremadamente importantes para el desarrollo cultural integral de una sociedad.

Ana Mae Barbosa apunta también hacia un objetivo englobante situado en una dimensión social que lo convierte en un principio de "política cultural":

"O que a arte/educação contemporânea pretende é formar o conhecedor, fruidor, decodificador da obra de arte. Uma sociedade só é artisticamente desenvolvida quando ao lado de uma produção artística de alta qualidade há também uma alta capacidade de entendimento desta produção pelo público. Desenvolvimento cultural que é a alta aspiração de uma sociedade só existe com desenvolvimento artístico neste duplo sentido" (Barbosa, 2010a, p. 33).

La argumentación desarrollada durante décadas por Ana Mae Barbosa sobre la importancia de la enseñanza del arte recorre un camino que tiene en cuenta tanto aspectos que conciernen al desarrollo cognoscitivo y emocional de niños y adolescentes, como a cuestiones contextuales, prácticas e instrumentales. Su concepción conceptual 
del arte, que hace énfasis en la dimensión cognoscitiva y por ende formativa, la sitúa en un enfoque esencialista; pero a la vez, al proyectar el objetivo último de la arteeducación en el horizonte de problemáticas históricas, sociales y culturales propias de Brasil, establece principios muy concretos de una "política cultural" inclusiva y democrática, lo cual la hace gravitar hacia un enfoque contextualista.

Sin ánimos de establecer una rígida caracterización, el Abordaje Triangular vendría a conjugar elementos argumentativos que se remiten a esos dos enfoques definidos por Elliot Eisner (1995). Ana Mae Barbosa no prescinde de una justificación esencialista, pero expande su propuesta hacia objetivos de carácter contextualista; de ahí que el Abordaje Triangular, además de proponerse como epistemología, ha intentado siempre dar respuesta a problemáticas concretas de la arte-educación en Brasil, partiendo de un anclaje profundamente histórico. ${ }^{11}$

La propia autora ha definido su Abordaje Triangularcomo constructivista, interaccionista, dialógico y multiculturalista; y por todo ello le considera una teoría posmoderna de enseñanza de arte. Según Barbosa, lo que define al posmodernismo en arte-educación es la articulación entre la "educación artística" - con énfasis en la creación de los estudiantes - y la "educación estética" - con énfasis en la apreciación para formar espectadores competentes (Barbosa, 1998, p. 41). Ese sería el gran paraguas dewiano, en su opinión.

La profesora e investigadora Rosa lavelberg (2017) coincide con esa definición marco de las concepciones posmodernas de enseñanza de las artes visuales; pero en lugar de John Dewey, es Viktor Lowenfeld el autor moderno que considera ha tenido mayor influencia en los teóricos contemporáneos (por lo menos en los que analiza en su libro). lavelberg acomete una exhaustiva sistematización de la arte-educación modernista y posmodernista, y una de sus conclusiones es que como generalidad, en la perspectiva contemporánea la enseñanza de arte exige del alumno acciones en diferentes ámbitos relacionados entre sí, como la producción, la fruición, la contextualización de las obras y las conexiones entre ellas. De esta manera se cumple, en su criterio, el propósito de estimular la formación potencial de artistas, y, al mismo tiempo, de espectadores competentes, con capacidad de juicio y selección crítica de la producción artística y cultural en general (p. 169-170).

En el Abordaje Triangular de Ana Mae Barbosa se pueden reconocer ciertamente muchos de los rasgos característicos de la arte-educación posmoderna que Rosa lavelberg (2017, p. 172-178) sistematiza en su libro, de entre los cuales podemos destacar:

Las concepciones posmodernas comienzan a trabajar el arte como objeto de conocimiento con contenidos propios. Además de la práctica creativa - que se sigue considerando importante -, en la concepción posmoderna los alumnos tienen

11 En un artículo reciente, titulado precisamente Em defesa da arte-educação, Ana Mae Barbosa recurre nuevamente a argumentos tanto contextualistas como esencialistas, y se refiere explícitamente a estos dos tipos de justificativas definidos por Elliot Eisner. (Barbosa, 2018, p. 66-74) 
la oportunidad de apreciar, fruir y reflexionar (la categoría que prefiera Ana Mae es "lectura de la obra de arte") sobre la mayor diversidad de producciones artísticas. Los contenidos de historia del arte y del sistema institucional del arte son incluidos como saberes, haciéndose énfasis en su contextualización histórica. Además de los medios y géneros tradicionales de las artes visuales, también son introducidos como contenidos las modalidades del arte contemporáneo en su gran diversidad de prácticas y procedimientos creativos.

Las concepciones posmodernas también favorecen la creación artística individual en el sentido autoral, pero se considera que la creatividad debe ser alimentada con el conocimiento de obras de arte y de la cultura visual en general. Se hace énfasis en la formación y desarrollo de competencias y habilidades cognitivas, procedimentales y sensoriales, tanto en el ámbito de la creación como en el estudio y conocimiento de la producción artística en su diversidad social, cultural e histórica. De ahí la importancia que se le otorga a que los alumnos se relacionen con obras de arte, ya sea en la escuela mediante reproducciones, o en visitas a museos, galerías e instituciones culturales, arte urbano etc. Se valora la necesidad de enseñar sobre la diversidad cultural y la interculturalidad presente en las obras, en la sociedad y en la vida de los individuos. Por ello, la organización de la enseñanza puede ser tanto disciplinar como interdisciplinar.

En la perspectiva posmoderna, además de trabajar a partir de los interese y necesidades de los alumnos, se considera que esos intereses también pueden ser generados y desarrollados por las propuestas didácticas y los contenidos elaborados por los profesores. Esto debido a que se vuelve dominante la tesis de que el desarrollo artístico no es natural, ni evoluciona de un estadio a otro de manera automática y progresiva. Se impone la perspectiva constructivista de que el conocimiento, las habilidades y las competencias en arte (como en otras áreas) dependen en buena medida del qué se enseña y del cómo se estructura didácticamente el aprendizaje.

La relación entre conocer-comprender el arte, y crear, se vuelve constitutiva del aprendizaje durante toda la educación básica. En ese tipo de aprendizaje significativo las experiencias y conocimientos previos que los alumnos son capaces de movilizar, se consideran fundamentales para que puedan interactuar con nuevos contenidos, ya sea en actividades de creación, apreciación y reflexión. Para Rosa lavelberg las concepciones posmodernas también innovaron con relación a las teorías modernistas, al introducir en las escuelas la reflexión, mediante la escritura u otro registro, sobre las experiencias artísticas que los alumnos practican de forma individual o colectiva, identificando significados expresivos y constructivos en los propios trabajos, de los compañeros y de los artistas. 
El Abordaje Triangular, considerado por la propia Ana Mae Barbosa como la primera concepción de arte-educación posmoderna en Brasil, ${ }^{12}$ debe ser comprendido en la órbita de esos criterios posmodernos de enseñanza de las artes visuales y en diálogo con muchos de los autores que les dan fundamento teórico. En esa constelación de autores Rosa lavelberg considera relevantes a John Matthews, David Hargreaves, Rod Taylor, Elliot Eisner, Gaeme Chalmers, Brent Wilson, Marjorie Wilson, Al Hurwitz, Arthur Efland, Sigmund Feldman, Michael Parsons, Abigail Housen, entre otros. Con varios de ellos dialoga explícitamente Ana Mae en su libro A imagen no ensino da arte, además de sistematizar los modelos didácticos de Edmund Feldman (método comparativo), Robert Saunders (método multipropósito), Monique Brière (DBAE con énfasis en la creación) y Rosalind Ragans (DBAE con énfasis en la crítica).

Ahora bien, la admirable obra investigativa de Ana Mae Barbosa siempre ha tenido como punto de partida las características específicas de Brasil, sus necesidades educacionales, su complejidad racial y cultural, sus desigualdades sociales, etc., por lo que las opciones teóricas asumidas por esta autora, aunque en sintonía con las tendencias internacionales, no han sido gratuitas, sino más bien exigencias del contexto histórico en el que ha desarrollado un pensamiento teórico y una práctica pedagógica. Para una pedagoga discípula de Paulo Freire, empeñada en que la educación cumpla un decisivo rol liberador, resultaba imprescindible una propuesta teórica que apostara por el reconocimiento de la creatividad del receptor, del papel activo de la conciencia que reacciona ante el estímulo del arte o de cualquier otro tipo de expresión simbólica. De ahí que el objetivo más ambicioso de su proyecto pedagógico a través del arte sea el de cultivar a todos los individuos en la lectura crítica del universo simbólico, como condición de posibilidad para una "alfabetización política" cada vez más democrática e inclusiva.

Como esa capacidad creativa y activa para relacionarse de manera crítica con los bienes simbólicos debe ser formada, desarrollada, la obra de Ana Mae Barbosa es hoy también un símbolo político que encarna la reivindicación y la lucha por el estatus central que debe tener el arte en la educación; y sobre todo, de la importancia de la inclusión de la lectura/comprensión de una variada oferta artística desde la enseñanza fundamental. Como ella misma ha reiterado en múltiples ocasiones, sería imposible romper el "apartheid cultural", ampliar el acceso al consumo artístico más allá de los sectores de élite, fomentar el diálogo intercultural, la movilidad del sujeto entre los diferentes códigos y registros culturales que coexisten en un país y en la sociedad global, si no se entrena al individuo, desde la más temprana infancia, en la interpretación/

12 Las políticas públicas educacionales en Brasil, a partir de 1996, seguirían esa ruta. Tanto en los Parámetros Curriculares Nacionales (Brasil, 1997; 1998), como en la Base Nacional Común Curricular (Brasil, 2017), se trasluce el enfoque posmoderno de enseñanza de arte. En los PCN se definen tres ejes articuladores del proceso de enseñanza-aprendizaje: "produção", "fruição", "reflexão" (para las series iniciales), y "produção", "apreciação", "contextualização" (para las series finales). Por su parte la BNCC, homologada a finales del 2017, establece seis dimensiones del conocimiento que se dice caracterizan la singularidad de la experiencia estética: "criação", "crítica”, "estesia”, "expressão", "fruição", "reflexão". De esta manera la recepción/comprensión del arte ha quedado consolidada en las políticas públicas como una dimensión de conocimiento esencial del componente curricular Arte. 
comprensión de esas peculiares objetivaciones mentales del "mundo humano" que son las obras de arte.

Data de submissão: 03/03/2019

Aceite: 03/06/2019

\section{Referencias}

Barbosa, A. M. (1998). Arte-educação pós-colonialista no Brasil: aprendizagem triangular. En A. M. Barbosa, Tópicos Utópicos (pp. 30-51). Belo Horizonte: C/Arte.

Barbosa, A. M. (2003). Arte Educação no Brasil: do modernismo ao pós-modernismo. Revista Digital Art\&, 0. Recuperado de http://www.revista.art.br/

Barbosa, A. M. (2009). Arte-educação no Brasil. São Paulo: Perspectiva.

Barbosa, A. M. (2010a). A imagem no ensino da arte: anos 1980 e novos tempos. São Paulo: Perspectiva.

Barbosa, A. M. (2010b). Da interdisciplinaridade à interterritorialidade: caminhos ainda incertos. Paidéia, 9, 11-29. Recuperado de http://www.fumec.br/revistas/paideia/article/view/1288

Barbosa, A. M. (2015). Além da cronologia. En Anais do 24 Encontro da ANPAP. Compartilhamentos na Arte: Redes e Conexões, Santa Maria, Brasil. Recuperado de http:// anpap.org.br/anais/2015/simposios/s6/ana_mae_barbosa.pdf

Barbosa, A. M. (2018). Em defesa da arte-educação. Observatório Itaú Cultural, 24, 66-75. Recuperado de http://www.itaucultural.org.br/revista-observatorio-24-arte-cultura-e-educacao-na-america-latina

Barbosa, A. M. y Cunha, F. (Eds.). (2010). A Abordagem triangular no ensino das artes e culturas visuais. São Paulo: Cortez.

BRASIL. (1997). Ministério da Educação. Parâmetros Curriculares Nacionais: Arte - Ensino Fundamental. - Brasília: MEC/SEF.

BRASIL. (1998). Ministério da Educação. Parâmetros Curriculares Nacionais: Arte - Ensino Fundamental. - Brasília: MEC/SEF.

BRASIL. (2017). Ministério da Educação. Base Nacional Comum Curricular (BNCC). -Brasília: MEC, CNE, CONSED, UNDIME.

Classen, C. Fundamentos de una antropología de los sentidos. Colección digital Los Mil 
y Un Textos en Una Noche. Volumen 1 (CD-ROM). La Habana: Centro Teórico-Cultural Criterios.

Eco, U. (1992). Los límites de la interpretación. Barcelona: Editorial Lumen.

Eco, U. (1988). Tratado de semiótica general. Barcelona: Editorial Lumen.

Eisner, E. (2005). Estrutura e mágica no ensino da Arte. En A. M. Barbosa. (Ed.), Arte-educação: leitura no subsolo (pp. 79-94). São Paulo: Cortez.

Eisner, E. (1995). Educar la Visión Artística. Paidos Ibérica.

Freire, P. (2004). La importancia de leer y el proceso de liberación. Siglo XXI Editores.

Gadamer, H. G. (1998). Verdad y método I. Salamanca: Ediciones Sígueme.

Gadamer, H. G. (1991). La actualidad de lo bello. El arte como juego, símbolo y fiesta. Barcelona: Ediciones Paidós.

Housen, A. (1999). El ojo del observador: investigación, teoría y práctica. Recuperado de www.vue.org

lavelberg, R. (2017). Arte/educação modernista e pós-modernista: fluxos na sala de aula. Porto Alegre: Penso.

Ingarden, R. (1987). Concretización y reconstrucción. En D. Rall. (Ed.), En busca del texto. Teoría de la recepción literaria (pp. 31-54). Universidad Nacional Autónoma de México.

Iser, W. (2003). El proceso de lectura. En N. Araújo y T. Delgado. (Eds.), Textos de teorías y crítica literarias (Del formalismo a los estudios postcoloniales (pp. 487-513). Universidad de La Habana, Universidad Autónoma Metropolitana de México.

Jakobson, R. (2003). Lingüística y poética. En N. Araújo y T. Delgado. (Eds.), Textos de teorías y crítica literarias (Del formalismo a los estudios postcoloniales (pp. 187-211). Universidad de La Habana, Universidad Autónoma Metropolitana de México.

Jameson, F. (1989). Documentos de cultura, documentos de barbarie. La narrativa como acto socialmente simbólico. Madrid: Visor.

Le Breton, D. (2007). El sabor del mundo. Una antropología de los sentidos. Buenos Aires: Nueva Visión.

Losada, T. (2011). A interpretação da imagem: subsídios para o ensino de arte. Rio de Janeiro: Mauad X: FAPERJ. 
Losada, T. (2017). O círculo (Isabel Allende), o quadrado (Antonio Dias) e o triângulo (Ana Mae Barbosa). Revista GEARTE, 4 (2), 231-245. Recuperado de http://seer.ufrgs. br/gearte

Mukařovský, J. (2000). Función, norma y valor estéticos como hechos sociales. En E. Volek y J. Jandová. (Eds.), Estética, función y valor: estética y semiótica del arte de Jan Mukařovský (pp. 127-203). Colombia: Plaza \& Janés Editores.

Parsons, M. (2008). Curriculum, arte e cognição integrados. En A. M. Barbosa. (Ed.), Arte/educação contemporânea: consonâncias internacionais (pp. 295-317). São Paulo: Cortez.

Popper, K. (1980). La lógica de la investigación científica. Madrid: Tecnos.

Revista GEARTE. (2017). Abordagem Triangular: territórios e perspectivas Arte/Educativas (Dossiê), Revista GEARTE, 4 (2), 163-364. Recuperado de http://seer.ufrgs.br/ gearte

Román, G. (2016). La relevancia de los sentidos en el arte contemporáneo: de los espacios polisensoriales de Frank Popper a la recepción distraída de Peter Osborne (tesis doctoral). Universidad de Granada, España. Recuperado de https://www.dialnet. unirioja.es.

Sonesson, G. (1997). De la estructura a la retórica en la semiótica visual. Signa: revista de la Asociación Española de Semiótica, 6. Recuperado de http://www.cervantesvirtual.com/obra-visor/signa-revista-de-la-asociacion-espanola-de-semiotica--13/html/ dcd92ce0-2dc6-11e2-b417-000475f5bda5_34.html\#l_51_

Welsh, W. (2011). Actualidad de la estética, estética de la actualidad. La Habana: Criterios.

\section{Biografia}

\section{Hamlet Fernández Díaz}

Doctor en Ciencias sobre Arte por la Universidad de La Habana, Cuba. Ha sido profesor de la Facultad de Artes y Letras de la Universidad de la Habana. Su trabajo académico, docente e investigativo, gira en torno a temas de estética, semiótica, hermenéutica, teoría del arte y educación artística. Es ensayista, curador, crítico de arte y medios audiovisuales. Ha obtenido en tres ocasiones el Premio Nacional de Crítica de Arte Guy Pérez Cisneros, que otorga el Consejo Nacional de las Artes Plásticas de Cuba. Con su libro de ensayo "La acera del sol... Impactos de la política cultural socialista en el arte cubano (1961-1981)", obtuvo el Premio de Ensayo Alejo Carpentier 2019, que otorga el Instituto Cubano del Libro y la Editorial Letras Cubanas. Es Miembro de la Unión 
Nacional de Escritores y Artistas de Cuba (UNEAC).

Email: hamletfdez84@gmail.com ORCID: https://orcid.org/0000-0001-68646359 